\title{
EDITORIAL
}

\section{The great mesh debate}

\author{
Robert M. Freeman • Gunnar Lose
}

Received: 29 April 2009/Accepted: 1 May 2009/Published online: 10 June 2009

(C) The International Urogynecological Association 2009

The introduction of mesh for pelvic floor reconstructive surgery has generated considerable debate regarding efficacy and safety. Of the few randomised controlled trials which exist, most are underpowered, and the data reported in systematic reviews are of poor quality [1, 2]. For example, in the one commissioned by the National Institute for Clinical Excellence (NICE) in the UK, the authors concluded: "The evidence for most efficacy and safety outcomes was too sparse to provide meaningful conclusions about the use of mesh/graft in anterior and/or posterior vaginal wall prolapse surgery" $[2,3]$. Therefore, these procedures should be considered experimental (i.e. a protocol should be available and results published (Declaration of Helsinki) until such evidence is available that patients can be counselled accordingly [4].

The innovative French TVM group who have pioneered the 'total vaginal mesh' concept give their opinion on this important subject in this month's edition of the IUJ [5]. Their views and recommendations are based on considerable experience with vaginal mesh procedures and backed up with audit and research data. They are to be commended for this evaluation and for

R. M. Freeman

Department of Urogynaecology, Plymouth Hospitals NHS Trust, Plymouth, UK

e-mail: robert.freeman@phnt.swest.nhs.uk

R. M. Freeman

Peninsula College of Medicine and Dentistry,

Plymouth, UK

G. Lose $(\bowtie)$

Department of Obstetrics and Gynaecology, Glostrup Hospital,

Ndr. Ringvej,

Glostrup 2600, Denmark

e-mail: gulo@glo.regionh.dk stating so clearly their disclosures or conflicts of interests. However, such good reporting is not universal: for example, since the introduction of the TVM in 2005, only $4,000(3 \%)$ of the 120,000 procedures performed worldwide have actually been reported (Ethicon Women's Health and Urology).

The use of new products implies innovative or experimental practices [6], and these should be rigorously audited. In the UK, NICE supports this and recommends that for all vaginal mesh procedures, clinicians should:

- Inform clinical governance leads

- Ensure that patients understand the uncertainty about long-term results and complications

- Provide patients with clear written information

- Audit and review clinical outcomes of all patients having mesh

In contrast to the introduction of new drug therapies, surgical procedures and devices can be marketed rapidly. In Europe, implants or devices require only CE marking, while in the USA, it is possible to market based on the socalled $510 \mathrm{~K}$ pre-market notification when a new material is deemed "substantially equivalent".

Why there should be a difference between the introduction of new surgical devices and drugs is unclear. It could be argued that the risks of surgery are greater than those of drug therapy; yet, their "governance" is less. Until properly designed comparative studies using both subjective and objective outcomes and long-term follow-up are undertaken, uncertainty regarding efficacy and safety will remain. In the meantime, it is hoped that industry and clinicians can work together in developing national databases to which surgeons will submit all their data including complications. Only in this way can we truly understand the outcomes of new surgical procedures and be able to counsel our patients. 
While large numbers of mesh repairs are undertaken worldwide without published outcomes, the data from the inventors of the TVM are helpful and provide useful information for patients and clinicians. It is also reassuring that manufacturers of mesh 'kits' are providing training courses and helping with audit.

As with any surgical procedure, complications arise, and the French TVM group feel that these are often: "overestimated, overemphasised, poorly described and inappropriately managed". They make an important point that it is relatively easy to publish a case report of a severe complication but that this can paint a falsely pessimistic picture. These reports might be interesting and important if there are lessons to be learnt from the case. However, it would be better if complications were properly classified (as the authors recommend) and reported to national databases so that the true incidence can be identified. This is unlikely to happen while voluntary reporting is the norm. In time, it is likely that government health departments will insist on all data being reviewed; it might be better if surgeons pre-empted this by collecting and reporting their own data rather than it being done by someone else.

\section{What is the evidence?}

The rationale for the use of mesh relates to the poor outcomes of traditional prolapse surgery especially for the anterior compartment. Te Linde stated over 40 years ago that: "every honest surgeon of extensive and long experience will have to admit that he/she is not entirely and absolutely satisfied with his/her long-term results of his/her operations for prolapse and allied conditions" [7]. It could be argued that not much has changed with $40 \%$ failure rates being quoted for anterior repair [8]. However, unlike surgery for urodynamic stress incontinence, the problem with most studies of prolapse surgery has been the lack of standardisation of outcome. Most studies have relied solely on anatomical outcomes and in those which have looked at subjective ones, there is a marked discrepancy between post-operative symptoms and anatomical results, i.e. there is lower subjective than objective or anatomical failure [9, 10]. There is, therefore, a need for patient reported outcomes related to expectations and goals, e.g. EGGS [11].

The argument that most women with anatomical failure will eventually require further surgery in the same compartment is unproven. For example, the much-quoted study by Olsen et al. [12] suggests that $11 \%$ of women will undergo surgery for prolapse during their lifetime and 29\% will require a second operation. However, these figures relate to both urinary incontinence and prolapse surgery rather than prolapse alone. From the same department, the
10 -year re-operation rate is almost $20 \%$, but when further surgery for the anterior compartment alone (i.e. the one that is most likely to recur anatomically) is analysed separately, the re-operation rate is only $4.6 \%$ [13]. This has been seen in other studies with re-operation rates for the anterior compartment of between $5 \%$ and $10 \%$ at intervals between 1 and 5 years after a primary "traditional" procedure [14-17]. While these re-operation rates are not synonymous with failure, nonetheless, one would imagine that if after "failed" primary surgery the symptoms were bothersome then patients would seek further treatment, whether that be with vaginal pessaries or surgery. Clearly, more research is needed to answer this question.

The debate regarding new surgical procedures such as mesh will continue until we have good-quality data from well-conducted randomised controlled trials of all vaginal prolapse surgery. One is due to commence shortly in the UK (Prolapse Surgery, Pragmatic Evaluation by Randomised Controlled Trial), and the results will be awaited with interest. It can be argued that data such as these should be available before mesh or any other surgical implant is marketed.

In the meantime, we must hope that national urogynaecology societies in collaboration with industry will set up databases and that all of us, as clinicians and surgeons, will submit our data, both "good" and "bad". Only then will we know the real outcomes of our surgery and be able to fully and effectively counsel our patients on the appropriate treatment for their pelvic organ prolapse.

\section{References}

1. Jia X, Glazener C, Mowatt G, MacLennan G et al (2008) Efficacy and safety of using mesh or grafts in surgery for anterior and/or posterior vaginal wall prolapse. BJOG 115:1350-1361

2. Feiner B, Jelovsek JE, Maher C (2009) Efficacy and safety of transvaginal mesh kits in the treatment of prolapse of the vaginal apex: a systematic review. BJOG 116(1):15-24

3. NICE (2008) Surgical repair of vaginal wall prolapse using mesh. (www.nice.org.uk/nicemedia/pdf/IPG267Guidance.pdf)

4. American College of Obstetricians and Gynecologists (2007) ACOG Practice Bulletin No 79, February 2007

5. Jacquetin B, Cosson M (2009) Complications of vaginal mesh: our experience. Int Urogynecol J Pelv Floor Dysfunct. doi:10.1007/s00192-009-0926-6

6. Lieberman V (2004) New technology and the orthopaedic surgeon. Clin Orthop Rel Res 429:338-341 ACOG Committee Opinion 2006 Innovative Practice: Ethical Guidelines: No 352

7. Te Linde RW (1959) A philosophy of pelvic surgery. Obstet Gynecol 14:253-256

8. Weber AM, Walters MD, Piedmonte MR, Ballard LA (2001) Anterior colporrhaphy: a randomised trial of three surgical techniques. Am J Obstet Gynecol 185:1299-1304 
9. Elkadry EA, Kenton KS, Fitzgerald MP, Shott S, Brubaker L (2003) Patient-selected goals: a new perspective on surgical outcome. Am J Obstet Gynecol 189:1551-1558

10. Whiteside JL, Weber AM, Meyn LA, Walters MD (2004) Risk factors for prolapse recurrence after vaginal repair. Am J Obstet Gynecol 191:1533-1538

11. Brubaker L, Shull R (2005) EGGS for patient-centered outcomes. Int Urogynecol J Pelvic Floor Dysfunct 16(3):171-173

12. Olsen AL et al (1997) Epidemiology of surgically managed pelvic organ prolapse and urinary incontinence. Obstet Gynecol 89:501506

13. Denman MA, Gregory WT, Boyles SH, Smith V, Edwards R, Clark AL (2008) Reoperation rate 10 years after surgically managed pelvic organ prolapse and urinary incontinence. Am J Obstet Gynecol 198:555.e1-555.e5
14. Hiltunen R, Nieminen K, Takala T, Heiskanen E, Merikari M, Niemei K, Heinonen PK (2007) Low-weight polypropylene mesh for anterior vaginal wall prolapse: a randomized controlled trial. Obstet Gynecol 110:455-462

15. Hawkins E, Raajkumar S, Masood M (2008) Long-term satisfaction with prolapse surgery in general gynaecology. Int Urogynecol J Pelvic Floor Dysfunct 19:1441-1448

16. Miedel A, Tegerstedt G, Morlin B, Hammarstrom M (2008) A 5year prospective follow-up study of vaginal surgery for pelvic organ prolapse. Int Urogynecol J Pelvic Floor Dysfunct 19:15931601

17. Diwadkar GB, Barber MD, Feiner B, Maher C, Jelovsek JE (2009) Complication and re-operation rates after apical vaginal prolapse surgical repair. Obstet Gynecol 113 (2):367-373 